\title{
Quaternised poly(4-vinylpyridine) anchored on a macroporous poly(trimethylolpropane trimethacrylate-methylmethacrylate) resin, as cocatalyst in the cobaltphthalocyanine catalysed oxidative coupling of 2-mercaptoethanol
}

\section{Citation for published version (APA):}

Ratering, M. T., Meuldijk, J., Piet, P., \& German, A. L. (1993). Quaternised poly(4-vinylpyridine) anchored on a macroporous poly(trimethylolpropane trimethacrylate-methylmethacrylate) resin, as cocatalyst in the cobaltphthalocyanine catalysed oxidative coupling of 2-mercaptoethanol. Reactive Polymers, Ion Exchangers, Sorbents, 19(3), 233-246. https://doi.org/10.1016/0923-1137(93)90081-P

DOI:

10.1016/0923-1137(93)90081-P

Document status and date:

Published: 01/01/1993

Document Version:

Publisher's PDF, also known as Version of Record (includes final page, issue and volume numbers)

Please check the document version of this publication:

- A submitted manuscript is the version of the article upon submission and before peer-review. There can be important differences between the submitted version and the official published version of record. People interested in the research are advised to contact the author for the final version of the publication, or visit the $\mathrm{DOI}$ to the publisher's website.

- The final author version and the galley proof are versions of the publication after peer review.

- The final published version features the final layout of the paper including the volume, issue and page numbers.

Link to publication

\footnotetext{
General rights

- You may freely distribute the URL identifying the publication in the public portal. follow below link for the End User Agreement:

www.tue.nl/taverne

\author{
Take down policy \\ If you believe that this document breaches copyright please contact us at: \\ openaccess@tue.nl \\ providing details and we will investigate your claim.
}

Copyright and moral rights for the publications made accessible in the public portal are retained by the authors and/or other copyright owners and it is a condition of accessing publications that users recognise and abide by the legal requirements associated with these rights.

- Users may download and print one copy of any publication from the public portal for the purpose of private study or research.

- You may not further distribute the material or use it for any profit-making activity or commercial gain

If the publication is distributed under the terms of Article $25 \mathrm{fa}$ of the Dutch Copyright Act, indicated by the "Taverne" license above, please 


\title{
Quaternised poly(4-vinylpyridine) anchored on a macroporous poly(trimethylolpropane trimethacrylate-methylmethacrylate) resin, as cocatalyst in the cobaltphthalocyanine catalysed oxidative coupling of 2-mercaptoethanol
}

\author{
M.T. Ratering ${ }^{a}$, J. Meuldijk ${ }^{b}$, P. Piet ${ }^{a}$ and A.L. German ${ }^{a}$ \\ ${ }^{a}$ Laboratory of Polymer Chemistry and ${ }^{b}$ Laboratory of Chemical Process Technology, \\ Eindhoven University of Technology, P.O. Box 513, 5600 MB Eindhoven, Netherlands
}

(Received November 13, 1992; accepted January 5, 1993)

\begin{abstract}
Immobilisation of expensive homogeneous catalysts is important for their application in commercial processes. Quaternised poly(4-vinylpyridine), which is a good promotor of the cobalt(II)phthalocyanine-tetra(sodium sulphonate) catalysed oxidative coupling of 2mercaptoethanol, has been anchored on a macroporous resin being prepared by copolymerisation of trimethylolpropane trimethacrylate and methyl methacrylate. The performance of the catalyst was only slightly lower than that of the homogeneous analogue. This remarkable result has been attributed to the large pores, which allow a post-copolymerisation of 4-vinylpyridine with the residual double bonds leading to a flexible and accessible polymeric cocatalyst.
\end{abstract}

Keywords: trimethylolpropane trimethacrylate; methyl methacrylate; quaternised poly(4vinylpyridine); macroporous resin; polymer catalyst; thiol oxidative coupling

\section{Introduction}

The effects of cationic polymers on the oxidative coupling of thiols into disulfides in the presence of cobalt(II)phthalocyanine-tetra(sodium sulphonate) (CoPcTS, see Fig. 1) have been extensively studied [1-3].

$4 \mathrm{RSH}+\mathrm{O}_{2} \rightarrow 2 \mathrm{RSSR}+2 \mathrm{H}_{2} \mathrm{O}$

Cationic polymers like protonated polyvinyl amine, quaternised poly(4-vinylpyridine) and poly(quaternary ammonium) salts (ionenes) strongly increase the reaction rate as compared with that observed for the conventional CoPcTS $/ \mathrm{OH}^{-}$system. For the application of the catalyst in continuous processes or for its reuse, immobilisation simplifies the operation.

Van Streun et al. [4] immobilised 2,4ionene onto a macroporous styrene-divinylbenzene resin (XAD-2). The modified resin has been used as a support for CoPcTS com- 


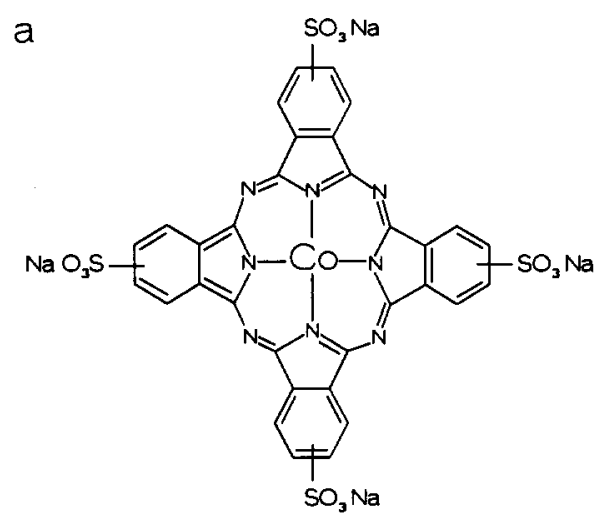

b<smiles>C=C(C)C(=O)OC</smiles>

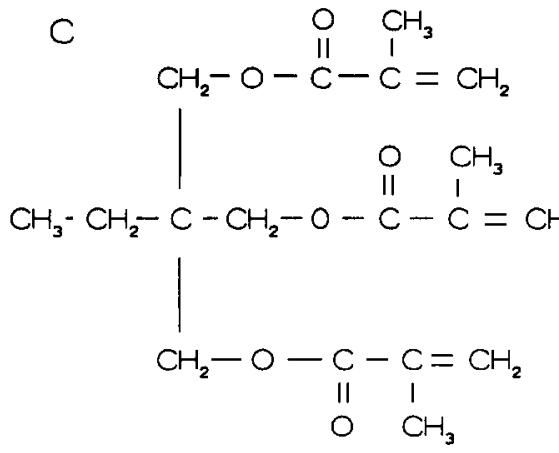

Fig. 1. Structures of (a) CoPcTS, (b) MMA and (c) TRIM.

plexes. A complete penetration of CoPcTS into the interior of the particles failed because the average pore diameter of $10 \mathrm{~nm}$ is too small to allow transport of the active complex. The number of accessible binding sites for CoPcTS is, therefore, lower than in the homogeneous system. Together with a reduced flexibility of the polymer chains in the pores and a rather unfavourable molar ratio of the cationic groups and the CoPcTS centres, this leads to a considerable loss of activity. Therefore, immobilisation with retention of the activity requires a resin with much larger pores. In such a case the microenvironment of the immobilised cationic polymer is approximately identical to that in the homogeneous situation, leading more or less to retention of the activity. Styrene-divinylbenzene is the most extensively studied macroporous polymer support [5,6]. The macroporous texture for these resins is obtained by using solvents in the presence of non-solvents or polymers as a porogenic diluent. Because the reactivity of divinylbenzenes in free radical polymerisation is significantly higher than that of styrene, a rather heterogeneous structure is obtained [6]. The preparation of copolymers of trimethylolpropane trimethacrylate (TRIM) and methyl methacrylate (MMA) (see Fig. 1) is less complicated, because the reactivity of both monomers is about the same [9]. Because of the promising properties of MMA/TRIM resins [7-9], these monomers were used to prepare a macroporous support by means of suspension polymerisation. The texture of the product strongly depends on the composition and the properties of the porogenic diluent. Because it is difficult to predict the effect of these parameters quantitatively, several polymerisations have been carried out to optimise the polymer structure in terms of the average pore size and the number of residual $\mathrm{C}=\mathrm{C}$ bonds. These $\mathrm{C}=\mathrm{C}$ bonds are the binding sites of poly(4-vinylpyridine), the precursor of the cationic polymer used in this study. However, the block length of the grafted copolymer is strongly affected by the copolymerisation kinetics, represented by the reactivity ratios of 4-vinylpyridine (4VP) (1) and the residual $\mathrm{C}=\mathrm{C}$ double bonds of TRIM (2). Possible reactions in the TRIM/MMA resin are presented in Fig. 2. If the reactivity of the $\mathrm{C}-\mathrm{C}$ bonds in the methacrylate moieties of TRIM in the resin is assumed to be the same as that in MMA, some qualitative predictions can be given using the reactivity 

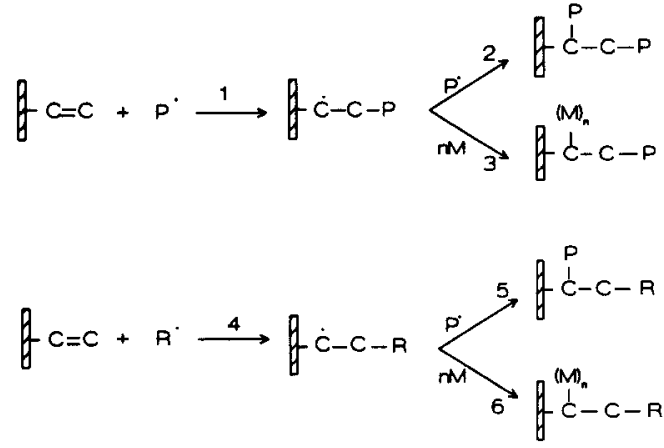

Fig. 2. Grafting of poly(4-vinylpyridine) (4VP) on the residual $\mathrm{C}=\mathrm{C}$ bonds of TRIM in the TRIM/MMA resin. P: 4VP oligomer radical; $\mathrm{M}$ : 4VP; $\mathrm{R}$ : initiator radical.

ratios of the system 4VP (1) and MMA (2). A convenient copolymerisation of 4VP (active) growing chains with the residual $\mathrm{C}=\mathrm{C}$ bonds in the resin may be expected from $r_{1}=0.99$ [10] (reaction 1 in Fig. 2). The value $r_{2}=0.54$ [10] suggests that the propagation of a 4VP polymer from the resin (reactions 3 and 6 in Fig. 2) can easily be performed. The cationic polymer can be formed by quaternisation of the pyridyl groups. The synthesis of this support and its performance towards the CoPcTS catalysed oxidative coupling of 2-mercaptoethanol is described in this paper.

\section{Experimental}

Synthesis of the polymer support

TRIM (Merck, purity > 90\%) and MMA (Merck, p.a.) were used without further purification. The copolymerisations were carried out in an all glass double walled cylindrical vessel $\left(2 \mathrm{dm}^{3}\right)$ equipped with 4 symmetrically located baffles. The impeller consisted of one set of three curved blades being placed at an angle of $10^{\circ}$ to the impeller shaft [11]. A resin with a macroporous structure was prepared using two different methods. In the first method, toluene and iso-octane were used as polymer solvent and polymer non-solvent, respectively. In the second procedure, a solution of poly(methyl meth- acrylate) (PMMA) in toluene was used as porogenic diluent.

A polymerisation reaction according to the first method was carried out by charging the reactor with $0.5 \mathrm{dm}^{3}$ water containing $1.5 \%$ poly(vinyl alcohol) by weight $\left(M_{\mathrm{w}}=72000\right.$, Koch Light Laboratories Ltd.), $35 \mathrm{ml}$ toluene and $35 \mathrm{ml}$ iso-octane. Subsequently, $0.31 \mathrm{~g}$ azo-bis(isobutyronitrile) (AIBN, 98\%, Janssen Chimica) dissolved in $6 \mathrm{ml}$ MMA and 24 $\mathrm{ml}$ TRIM were added to the reactor. The impeller speed was adjusted to $300 \mathrm{rpm}$ and the reaction mixture was treated with argon during $15 \mathrm{~min}$ to remove oxygen. After this the reaction was started by heating the reactor to $60^{\circ} \mathrm{C}$. During the reaction an argon atmosphere was maintained. After $16 \mathrm{~h}$, the reaction mixture was cooled to room temperature.

For the second method the procedure was modified to some extent. The reactor was charged with $250 \mathrm{ml}$ water, $7.5 \mathrm{~g} \mathrm{NaCl}, 0.25 \mathrm{~g}$ gelatin and $1.5 \mathrm{~g}$ of an aqueous solution containing $25 \%$ poly (acrylic acid, sodium salt) by weight $\left(M_{\mathrm{w}}=140000\right.$, Polysciences Inc.) [12]. The $\mathrm{pH}$ of the water phase was adjusted to a value between 8 and 9 with a few drops of concentrated ammonia. Subsequently, 0.47 g AIBN dissolved in a mixture of $9 \mathrm{ml}$ MMA, $36 \mathrm{ml}$ TRIM and $80 \mathrm{ml}$ toluene containing $15 \%$ PMMA by weight $\left(M_{\mathrm{w}}=79500, M_{\mathrm{n}}=\right.$ 42700 by gel permeation chromatography) were added to the reactor. The polymerisation temperature was kept at $70^{\circ} \mathrm{C}$ and the reaction time was $20 \mathrm{~h}$.

The products were filtered on a glass filter, washed two times with water and extracted overnight with acetone in a Soxhlet apparatus. The polymer beads were subsequently dried in a vacuum at $60^{\circ} \mathrm{C}$ for $24 \mathrm{~h}$, and sieved in an air jet sieve.

Immobilisation of poly(4-vinylpyridine) on the resin

Before use 4VP (Janssen Chimica, 95\% pure) was distilled under reduced pressure 
( $P=40 \mathrm{~Pa}, T=34^{\circ} \mathrm{C}$ ) and carefully stored under an argon atmosphere at $-18^{\circ} \mathrm{C}$. A 5 ml crimp top flask (Chrompack) was charged with $0.5 \mathrm{~g}$ resin, $4 \mathrm{ml} \mathrm{4VP}$ and $39.1 \mathrm{mg}$ AIBN $\left(1 \% \mathrm{w} / \mathrm{w}_{\text {monomer }}\right)$. The vial was capped with a teflon coated rubber septum, which was punctured by two needles, one for the argon inlet and one for the argon outlet. Argon was bubbled through the flask during $15 \mathrm{~min}$ and the needles removed. The resin was equilibrated during $15 \mathrm{~h}$. Reaction times were varied between 15 and $60 \mathrm{~min}$; the temperatures were varied between 60 and $65^{\circ} \mathrm{C}$. The reaction was stopped by cooling the vial in ice. Dissolved P4VP was removed from the resin by washing with ethanol on a glass filter until precipitation of P4VP could not be observed when the filtrate was poured into acetone. This washing procedure took about $24 \mathrm{~h}$. Several reactions were carried out with different reaction times and temperatures.

Quaternisation of the immobilised poly(4vinylpyridine)

A glass tube containing $3 \mathrm{~g}$ resin, $20 \mathrm{ml}$ DMF and $5 \mathrm{ml}$ methyl iodide, connected to a vacuum pump and a nitrogen gas supply by means of a three way valve, was cooled with liquid nitrogen and evacuated. After this, nitrogen was introduced and the tube was allowed to reach room temperature. Before sealing the evacuated tube, this procedure was repeated twice. The quaternisation process was carried out at $80^{\circ} \mathrm{C}$, the reaction time was $30 \mathrm{~h}$. The product was treated with deionised water until the conductivity of the surrounding liquid was lower than $1 \mu \mathrm{S} \mathrm{cm}^{-1}$. The resin was stored in deionised water.

\section{Characterisation}

Mercury porosimetry (Carlo Erba Strumentazione, Series 200) was used to determine the pore size distribution for pores larger than $3.75 \mathrm{~nm}$.

The intraparticle surface area was measured by nitrogen adsorption according to the BET method (Areameter, Stroelein).

The intraparticle morphology was investigated with scanning electron microscopy (SEM) (Cambridge S 2000).

The reduction of the residual double bonds in the resin resulting from the reaction with 4VP was estimated with IR spectroscopy (Mattson, Polaris Fourier Transform Infrared Spectrophotometer). For this purpose the ratio of the absorbances of the $\mathrm{C}=\mathrm{C}$ stretch vibration at $1639 \mathrm{~cm}^{-1}$ and the $\mathrm{C}=\mathrm{O}$ stretch vibration at $1731 \mathrm{~cm}^{-1}$ of TRIM in

\section{TABLE 1}

Characteristics of TRIM/MMA resins prepared by suspension polymerisation using several recipes

\begin{tabular}{lllllll}
\hline No. & $\begin{array}{l}\text { Solvent } \\
\text { non-solvent } \\
\text { ratio (v/v) }\end{array}$ & $\begin{array}{l}\text { Diluent } \\
\text { monomer } \\
\text { ratio }(\mathrm{v} / \mathrm{v})\end{array}$ & $\begin{array}{l}\text { MMA/TRIM } \\
\text { ratio }(\mathrm{v} / \mathrm{v})\end{array}$ & $\begin{array}{l}\text { Pore volume } \times 10^{3} \\
\left(\mathrm{~m}^{3} / \mathrm{kg}\right)\end{array}$ & $\begin{array}{l}\text { Mean pore } \\
\text { radius } \times 10^{9} \\
(\mathrm{~m})\end{array}$ & $\begin{array}{l}\text { Residual double } \\
\text { bonds of TRIM } \\
(\mathrm{mol} / \mathrm{mol} \text { TRIM })\end{array}$ \\
\hline 1 & $25 / 75$ & $70 / 30$ & $0 / 100$ & 0.19 & $<30$ & $1.2 \pm 0.2$ \\
2 & $50 / 50$ & $70 / 30$ & $0 / 100$ & 0.37 & $<50$ & $0.7 \pm 0.2$ \\
3 & $50 / 50$ & $70 / 30$ & $10 / 90$ & 0.65 & 8 & $0.4 \pm 0.1$ \\
4 & $50 / 50$ & $70 / 30$ & $20 / 80$ & 0.69 & 1050 & $0.33 \pm 0.03$ \\
5 & $50 / 50$ & $50 / 50$ & $20 / 80$ & 0.43 & 1330 & \\
6 & $50 / 50$ & $30 / 70$ & $20 / 80$ & 0.12 & $<60$ & - \\
7 & $\mathrm{a}$ & $64 / 36$ & $20 / 80$ & 0.87 & $<30$ & - \\
\hline
\end{tabular}

\footnotetext{
a The porogenic diluent was a $15 \%$ PMMA solution by weight in toluene.
} 
the resin before and after modification with 4VP was used. The observed absorbance at $1731 \mathrm{~cm}^{-1}$ was corrected for the contribution of the $\mathrm{C}=\mathrm{O}$ stretch vibration of the MMA units. For this correction the molar ratio of TRIM and MMA in the mixture before the suspension polymerisation was assumed to be equal to that in the resin. Further, the molar absorbances of the $\mathrm{C}=\mathrm{O}$ stretch vibration of TRIM and MMA were approximated to be equal.

The nitrogen content in the resin after the post copolymerisation with 4VP was determined by elemental analysis.

The degree of quaternisation was estimated from IR spectra using the ratio of the absorbance of the pyridine ring vibration at $1599 \mathrm{~cm}^{-1}$ and that of the $\mathrm{C}=\mathrm{O}$ stretch vibration at $1731 \mathrm{~cm}^{-1}$.

The degree of quaternisation was also determined for some samples in which the iodide was first exchanged by $\mathrm{OH}^{-}$. These samples were treated with an excess of an aqueous $10^{-2} M \mathrm{HCl}$ solution. The excess $\mathrm{HCl}$ was titrated back with an aqueous $10^{-2}$ $M \mathrm{NaOH}$ solution. During this potentiometric titration two equivalence points were observed: one corresponding with the excess free $\mathrm{HCl}$, the other one, at a higher $\mathrm{pH}$, corresponding with the deprotonation of the pyridine groups, which are not quaternised.

\section{Catalyst preparation}

Support particles with a diameter of $\sim 25$ $\mu \mathrm{m}$ were obtained by crushing the dried resin containing $0.3 \% \mathrm{~N}$ by weight in a mortar using liquid nitrogen, and sieving the resulting material in an air jet sieve. The mean particle size was determined by SEM. Hereafter the resin particles were dispersed in water and the water swollen resin particles were filtered off.

An aqueous $2 \times 10^{-4} \mathrm{M}$ CoPcTS solution was added to an aqueous slurry containing $20 \%$ by weight of the water swollen resin.
After the addition of CoPcTS which took $\sim 1 \mathrm{~h}$, the slurry was shaken overnight. The adsorption process was carried out in an argon atmosphere. Oxygen was excluded carefully. The concentration of CoPcTS in the liquid surrounding the particles was determined using UV/VIS spectrometry (Hewlett-Packard diode array spectrophotometer, $\lambda=662 \mathrm{~nm}[4]$ ).

The distribution of CoPcTS over the resin particle was investigated by SEM. The CoPcTS loaded resin was stored in water. Before use the adhering water was removed by centrifugation. The remaining water content of the resin was $59.6 \%$ by weight.

\section{Kinetic runs}

The equipment for the measurement of the rates of the batchwise oxidative coupling of mercaptoethanol (ME) has been described by van Herk et al. [13].

The reaction medium consisted of 0.005 to $0.2 \mathrm{~g}$ of the water swollen resin and $0.1 \mathrm{dm}^{3}$ distilled water. Before the reaction was started, the vessel was evacuated to $\sim 0.5$ $\mathrm{kPa}$ and subsequently filled with oxygen under stirring (8 rps) until a partial oxygen pressure of $0.1 \mathrm{MPa}$ was reached. This process was repeated twice. The desired $\mathrm{pH}$ was obtained by adding a small amount of an aqueous saturated sodium hydroxide solution. The reaction was started by injecting $\mathrm{ME}$ into the slurry. The reaction rate was determined by monitoring the oxygen consumption rate during the reaction.

\section{Results and discussion}

\section{Preparation of the polymer support}

The optimisation of the intraparticle morphology of the TRIM/MMA resin has been carried out by a variation of the volumetric ratio of the monomers and the porogenic 
diluent, the volumetric ratio of MMA and TRIM, and the nature and the composition of the diluent. The results of the characterisation of the isolated products in terms of pore size, pore volume and unreacted double bonds have been collected in Table 1. This table shows that resins with pores larger than $1 \mu \mathrm{m}$ were obtained for copolymerisations with a 1:1 mixture of toluene and iso-octane and a large volumetric ratio of the diluent and the monomers. These resins also show a bimodal pore size distribution. A macroporous resin with very large pores has also been obtained by using a solution of PMMA in toluene as diluent (resin 7 in Table 1). This resin has an unimodal pore size distribution, see Fig. 3. The mean pore size is $\sim 0.7 \mu \mathrm{m}$. Similar results have been reported by Revillon et al. [14], who prepared styrene-divinylbenzene resins with a solution of polystyrene in toluene as the porogenic diluent. Vigorous stirring of a $10 \%$ slurry in the reactor used for the kinetic experiments with an energy input of $\sim 70 \mathrm{~W} / \mathrm{kg}$, showed that the mechanical strength of the resin prepared with a PMMA solution as a diluent is better than that of the resins obtained with

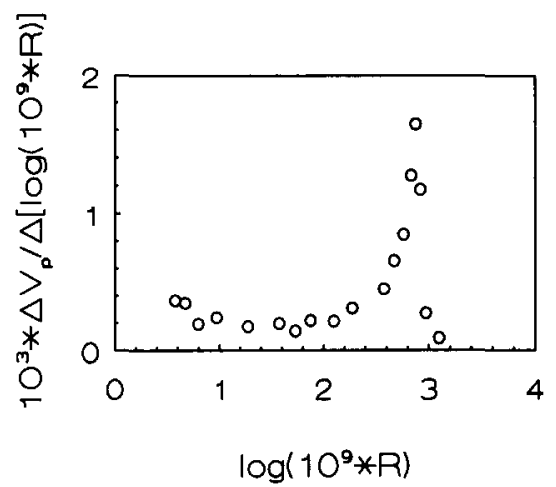

Fig. 3. Pore size distribution of the TRIM/MMA resin prepared with a porogenic diluent solution of $15 \%$ PMMA by weight in toluene. Initial volume ratio of MMA and TRIM: 2/8; volume ratio of the diluent solution and the monomers: $7 / 3$. Units: $V_{\mathrm{p}}$ in $\mathrm{m}^{3} / \mathrm{kg}$ and $R$ in $\mathrm{m}$.

mixture of toluene and iso-octane. SEM micrographs of the resins prepared with the PMMA solution showed no significant difference between the particle sizes before and after a stirring period of $15 \mathrm{~min}$. Because this resin combines a good mechanical strength, a large pore size and a reasonable number of residual double bonds, it was used as the starting material for the post copolymerisation with 4VP.

\section{TABLE 2}

Results of the post-copolymerisation of a TRIM/MMA ${ }^{a}$ resin with 4-vinylpyridine

\begin{tabular}{|c|c|c|c|c|c|}
\hline No. & Reaction & $\begin{array}{l}\text { Conversion of } \\
\text { 4-vinylpyridine } \\
(\%)^{b}\end{array}$ & $\begin{array}{l}\text { Poly(4-vinylpyridine) } \\
\text { modified resin ratio } \\
\text { (\% by weight) }\end{array}$ & $\begin{array}{l}\text { Pore volume } \times 10^{3} \\
\left(\mathrm{~m}^{3} / \mathrm{kg}\right)\end{array}$ & $\begin{array}{l}\text { Specific area } \times 10^{-3} \\
\left(\mathrm{~m}^{2} / \mathrm{kg}\right)\end{array}$ \\
\hline 1 & $\begin{array}{l}\text { resin +4VP } \\
t=30 \mathrm{~min} \\
T=65^{\circ} \mathrm{C}\end{array}$ & $22 \pm 6$ & 34 & 0.44 & 42 \\
\hline 2 & $\begin{array}{l}\text { resin }+4 \mathrm{VP} \\
t=15 \mathrm{~min} \\
T=65^{\circ} \mathrm{C}\end{array}$ & $13 \pm 4$ & 6.90 & 0.61 & 93 \\
\hline 3 & $\begin{array}{l}\text { resin }+4 \mathrm{VP} \\
t+15 \mathrm{~min} \\
T=60^{\circ} \mathrm{C}\end{array}$ & $9 \pm 4$ & 2.55 & 0.70 & 125 \\
\hline
\end{tabular}

\footnotetext{
${ }^{a}$ Resin prepared with a 15\% PMMA solution by weight in toluene (resin No. 7 in Table 1).

b The conversions were determined with gas chromatography (Hewlett-Packard Gas chromatograph, model 5700A, equipped with a $10 \%$ carbowax column) using cyclohexanol as an internal standard.
} 
Post-copolymerisation of the resin with 4vinylpyridine

The influence of the reaction time and the temperature on the P4VP loading has been investigated. The results are presented in Table 2. This table shows that the resin with $2.6 \%$ P4VP by weight has the largest pore volume and intraparticle area. This resin together with that containing $34 \%$ P4VP by weight were used for a further modification.

The average block length of the grafted P4VP was estimated from the reduction of the residual $\mathrm{C}=\mathrm{C}$ bonds of TRIM during the copolymerisation and the total amount of 4VP immobilised in the resin. For a resin with a final P4VP weight fraction of 0.34 , a reduction of the $\mathrm{C}=\mathrm{C}$ bonds from 0.48 to 0.19 was observed. For this resin the average block length was estimated to be 11 . This calculation procedure, however, may result in an underestimation of the block length because reaction of the initiator with the residual double bonds of TRIM does not necessarily lead to an effective graft site. For lower weight fractions of P4VP the decrease of the residual $\mathrm{C}=\mathrm{C}$ bonds of TRIM was too small to be estimated with acceptable accuracy. However, considering the reactivity ratios of $4 \mathrm{VP}$ and the methyl methacrylate groups [10], block lengths comparable with those in the resin containing $34 \%$ P4VP may be expected. Schutten et al. [15] suggested that the upper limit of the block length may be equated to the degree of polymerisation of the homopolymerised 4VP extracted from the resin. Viscosity measurements showed that the number average degree of polymerisation for this polymer is $\sim 120$.

Unfortunately a more accurate determination of the block length of the grafted P4VP is not yet possible.

\section{Quaternisation}

Figures $4 a$ and $b$ show the IR spectra of the resin containing 34\% P4VP before and after the reaction with methyl iodide, respectively. The absorbance of the pyridine ring vibration after the reaction is much lower than that of the starting material, which indicates a high degree of quaternisation. From

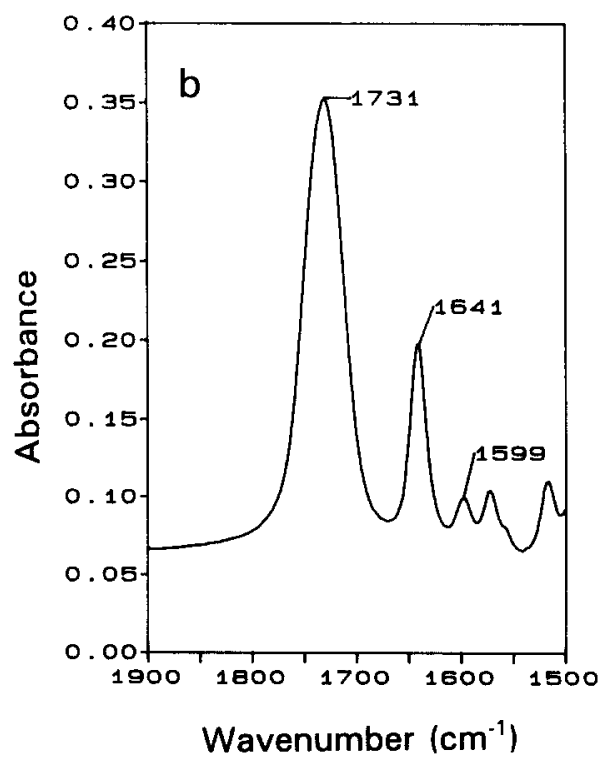

Fig. 4. IR spectra of the TRIM/MMA resin before (a) and after (b) quaternisation of the grafted poly(4-vinylpyridine) chains. 
the ratio of the absorbances of the pyridine ring vibration at $1599 \mathrm{~cm}^{-1}$ and the $\mathrm{C}=\mathrm{O}$ stretch vibration at $1731 \mathrm{~cm}^{-1}$ it can be estimated that $80-90 \%$ of the pyridine moieties are quaternised. The degree of quaternisation of resins containing 2.6\% P4VP by weight could not be determined with IR spectroscopy, because the intensity of the absorption band assigned to the pyridine ring vibration is too low. Potentiometric titrations also show that for this resin $80-90 \%$ of the pyridine rings are quaternised.

\section{Adsorption of CoPcTS}

The modified TRIM/MMA resin with a mean pore size of $700 \mathrm{~nm}$, a P4VP content of $2.6 \%$ by weight and a degree of quaternisation of $80-90 \%$ has been used for the kinetic experiments. The maximum amount of CoPcTS which can be adsorbed by this resin is $5.3 \times 10^{-4}$ mol per $\mathrm{kg}$ of the water swollen resin. SEM micrographs showed that CoPcTS was only adsorbed in the outer shell of the resin particles. The penetration depth was $\sim 10 \%$ of the particle radius.

Performance of the catalyst towards the oxidative coupling of 2-mercaptoethanol

Reaction rates of the oxidative coupling of thiols depend on the CoPcTS loading on the catalyst support, the concentration of thiol and oxygen, the $\mathrm{pH}$ and resistances against mass transfer.

Figure 5 shows the influence of the $\mathrm{pH}$ on the initial oxygen consumption rate per unit of mass of the water swollen resin $\left[-r_{\mathrm{O}_{2}}^{w}\right.$ $\left.\left(\mathrm{mol} /\left(\mathrm{kg}_{\text {resin }} \cdot \mathrm{s}\right)\right)\right]$ for two mercaptoethanol concentrations. The results show that the rate increases considerably with the $\mathrm{pH}$ for $7<\mathrm{pH}<10$. For higher $\mathrm{pH}$ values the rate remains almost constant within experimental error. The initial increase of the rate can be explained by realising that the thiolate anion is the reactive species in the CoPcTS catal-

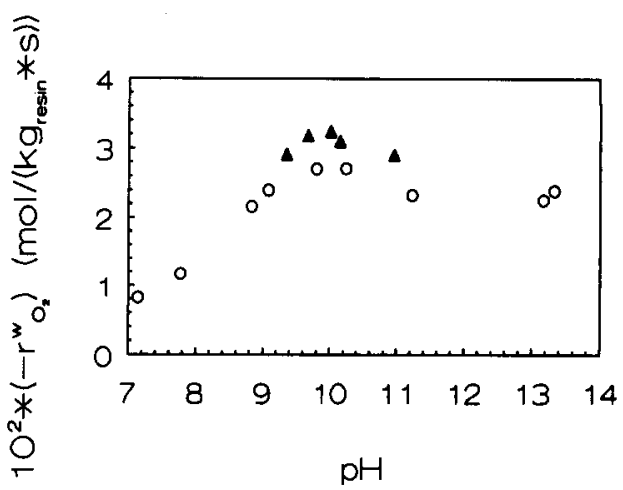

Fig. 5. Reaction rates, $-r_{\mathrm{O}_{2}}^{\mathrm{w}}$, of the CoPcTS catalysed oxidative coupling of 2-mercaptoethanol as a function of the $\mathrm{pH} . T=(25.0 \pm 0.1)^{\circ} \mathrm{C}$; oxygen partial pressure: $0.1 \mathrm{MPa} ; V_{\mathrm{L}}=10^{-4} \mathrm{~m}^{3} ;$ [CoPcTS] $=3.6 \times 10^{-4}$ $\mathrm{mol} / \mathrm{kg}_{\text {resin }} ;$ [resin] $=1.0 \mathrm{~kg} / \mathrm{m}_{\mathrm{L}}^{3} ;$ [ME]: (O) 143 $\mathrm{mol} / \mathrm{m}_{\mathrm{L}}^{3} ;$ ( $\left.\Delta\right) 286 \mathrm{~mol} / \mathrm{m}_{\mathrm{L}}^{3}$.

ysed oxidative coupling of thiols [16]. For $\mathrm{pH}$ values above about 10 the chemisorption of hydroxide ions will considerably compete with that of the thiolate anions. This competition leads to a slightly decreasing rate on increasing the $\mathrm{pH}$ above $\sim 10$.

Reaction rates as a function of the initial mercaptoethanol concentrations are collected in Fig. 6. The results show a tendency towards saturation for mercaptoethanol concentrations above $\sim 150 \mathrm{~mol} / \mathrm{m}_{\mathrm{L}}^{3}$. This saturation effect is comparable with that of a latex system, prepared by emulsion copolymerisation of styrene and divinylbenzene in

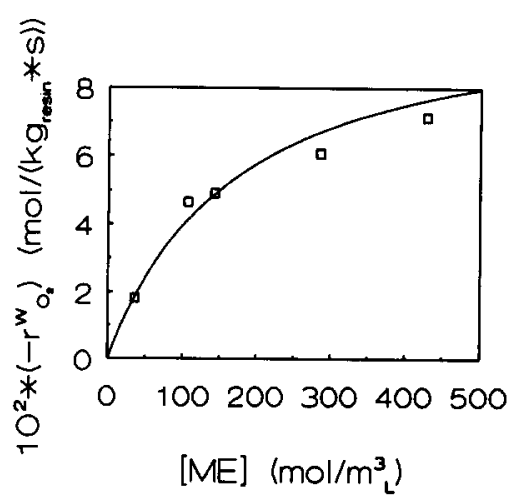

Fig. 6. Reaction rates, $-r_{\mathrm{O}_{2}}^{\mathrm{w}}$, as a function of the mercaptoethanol concentration. $\mathrm{pH}=(10.0 \pm 0.3)$; [re$\sin ]=0.5 \mathrm{~kg} / \mathrm{m}_{\mathrm{L}}^{3}$; for other conditions, see Fig. 5 . 
the presence of a block copolymer of styrene and 4-vinylpyridinium iodide [17]. For homogeneous 2,4-ionene [16], the 2,4-ionene/ $\mathrm{XAD}-2$ resin [4] and homogeneous qP4VP [17] saturation effects have been observed at significantly lower substrate concentrations. After a discussion concerning mass transport, the differences between these catalyst systems are discussed more quantitatively.

The reaction rates $\left(-r_{\mathrm{O}_{2}}^{\mathrm{w}}\right)$ as a function of the CoPcTS loading of the support are collected in Fig. 7. For CoPcTS concentrations up to $0.35 \times 10^{-3} \mathrm{~mol} / \mathrm{kg}_{\text {resin }}$ there is a linear relationship between the reaction rate and the catalyst loading. Higher CoPcTS concentrations do not result in a significantly more active catalyst. The quite sudden change of the influence of the CoPcTS concentration on the rates may be attributed to a lack of residual binding sites for CoPcTS in the resin or by some precipitation of the Co complex. In the absence of CoPcTS the resin shows some residual activity towards the oxidative coupling of mercapoethanol. For a poly(styrene-b-qP4VP) latex system no activity has been observed without CoPcTS [17].

Transformation of the observed rate data into the intrinsic performance of the catalyst requires a quantitative insight into possible mass transfer resistances. The mercaptoethanol concentration in the liquid phase

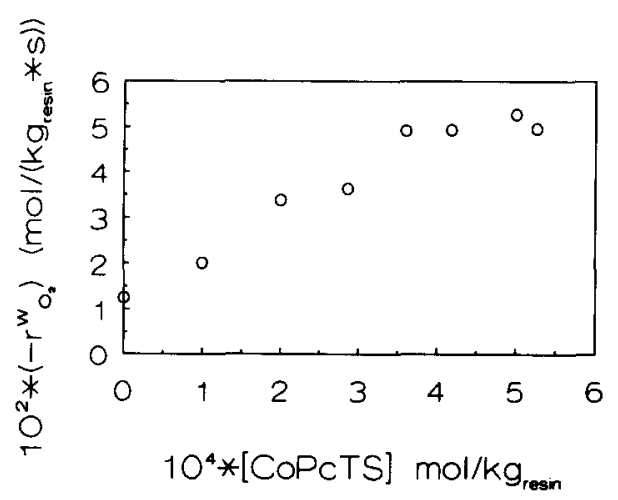

Fig. 7. Reaction rates, $-r_{\mathrm{O}_{2}}^{\mathrm{w}}$, as a function of the CoPcTS concentration in the modified TRIM/MMA resin. $[M E]=143 \mathrm{~mol} / \mathrm{m}_{\mathrm{L}}^{3} ;$ [resin] $=0.5 \mathrm{~kg} / \mathrm{m}_{\mathrm{L}}^{3} ; \mathrm{pH}=$ $(10.0 \pm 0.3)$; for other conditions, see Fig. 5 .

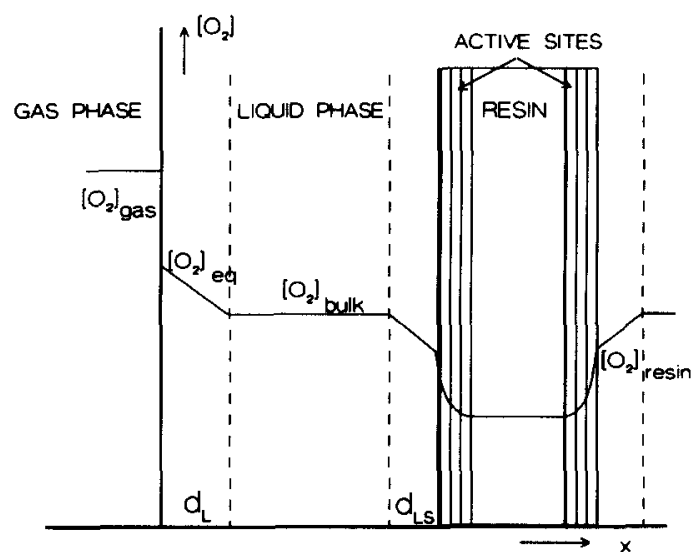

Fig. 8. Concentration profile of oxygen in the gas, liquid and resin phase according to the film model. $d_{\mathrm{L}}$ and $d_{\mathrm{LS}}$ stand for the film thickness at the liquid side of the gas/liquid interface, and the film thickness at the liquid side of the liquid/resin interface, respectively.

exceeds the equilibrium concentration of oxygen by more than one order of magnitude. As a result the influence of transport of mercaptoethanol from the bulk liquid to the active sites on the rates is considered to be negligible. Therefore, only mass transport of oxygen has to be considered. Significant resistances can be located in the gas/liquid and the liquid/resin interface, see Fig. 8. Further, intraparticle diffusion limitation may have some influence on the performance of the catalyst. The linear relation between the molar absorption flow rate of oxygen $\left[-R_{\mathrm{O}_{2}}\right.$ $(\mathrm{mol} / \mathrm{s})]$ and the concentration of the resin presented in Fig. 9, shows that the resistance against oxygen transport through the gas/ liquid interface is negligible. The oxygen concentration in the bulk liquid can therefore be equated to the equilibrium concentration corresponding to the oxygen partial pressure in the gas phase. Oxygen transport from the bulk liquid to the outer surface of the resin particles can be described by:

$$
\begin{array}{r}
-R_{\mathrm{O}_{2}}= \\
k_{\mathrm{LS}} \times\left(\left[\mathrm{O}_{2}\right]_{\text {bulk }}-\left[\mathrm{O}_{2}\right]_{\text {resin }}\right) \\
\times \frac{6}{\rho_{\text {resin }} \times d_{\mathrm{p}}} \times W_{\text {resin }} \times V_{\mathrm{L}}
\end{array}
$$




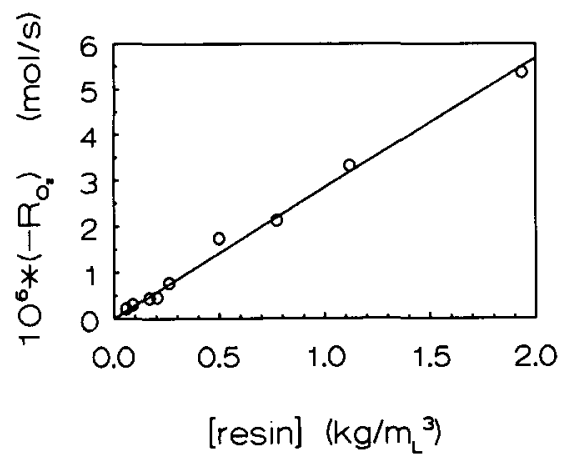

Fig. 9. Oxygen consumption rates, $-R_{\mathrm{O}_{2}}$, as a function of the resin concentration. [ME] $=143 \mathrm{~mol} / \mathrm{m}_{\mathrm{L}}^{3} ; \mathrm{pH}=$ $(10.0 \pm 0.3)$; for other conditions, see Fig. 5 .

with

$-R_{\mathrm{O}_{2}}=-r_{\mathrm{O}_{2}}^{\mathrm{w}} \times W_{\text {resin }} \times V_{\mathrm{L}}$

where $k_{\mathrm{LS}}(\mathrm{m} / \mathrm{s}), \rho_{\text {resin }}\left(\mathrm{kg} / \mathrm{m}_{\text {resin }}^{3}\right), d_{\mathrm{p}}(\mathrm{m})$, $W_{\text {resin }}\left(\mathrm{kg}_{\text {resin }} / \mathrm{m}_{\text {water }}^{3}\right)$ and $V_{\mathrm{L}}$ stand for the mass transfer coefficient for oxygen transport between the bulk liquid and the outer resin surface, the density of the water swollen resin, the mean diameter of the resin particles, the resin concentration and the volume of the liquid phase $\left(10^{-4} \mathrm{~m}_{\text {water }}^{3}\right)$, respectively. In all calculations the value of $d_{\mathrm{p}}$ is $25 \times 10^{-6} \mathrm{~m}$. For $\rho_{\text {resin }}$ an estimated value of $1000 \mathrm{~kg} / \mathrm{m}_{\text {resin }}^{3}$ was used. For:

$0.0229<\frac{\epsilon^{1 / 3} \times d_{\mathrm{p}}^{4 / 3}}{\nu}<495$

$k_{\mathrm{LS}}$ can be estimated by the following correlation reported by Asai et al. [18]:

$$
\begin{aligned}
\frac{k_{\mathrm{LS}} \times d_{\mathrm{p}}}{D_{\mathrm{O}_{2}}}= & {\left[2^{5.8}+\left\{0.61\left(\epsilon^{1 / 3} d_{\mathrm{p}}^{4 / 3} / \nu\right)^{0.58}\right.\right.} \\
& \left.\left.\times\left(\nu / D_{\mathrm{O}_{2}}\right)^{1 / 3}\right\}^{5.8}\right]^{1 / 5.8}
\end{aligned}
$$

For the molecular diffusion coefficient of oxygen in water, $D_{\mathrm{O}_{2}}=2.5 \times 10^{-9} \mathrm{~m}^{2} / \mathrm{s}$ [19], the kinematic viscosity of water, $\nu=0.9 \times$ $10^{-6} \mathrm{~m}^{2} / \mathrm{s}$ and the power input of the impeller, $\epsilon=71.4 \mathrm{~W} / \mathrm{kg}$, calculated according to Bates et al. [20] with an impeller speed of $43.3 \mathrm{rps}$, the liquid-to-resin mass transfer coefficient, $k_{\mathrm{LS}}$, has been calculated to be $(0.9$ $\pm 0.3) \times 10^{-3} \mathrm{~m} / \mathrm{s}$. Using the same value of $\epsilon$ an almost identical result can be found with the equation derived by Sano et al. [21]. The latter relation has been used by Van Streun et al. [4] to describe mass transfer to the 2,4-ionene/XAD-2 resin. For $\left[\mathrm{O}_{2}\right]_{\text {resin }}>$ $0.95 \times\left[\mathrm{O}_{2}\right]_{\text {bulk }}$ the influence of oxygen mass transport from the bulk liquid to the outer surface of the resin may be considered to be negligible. For $\left[\mathrm{O}_{2}\right]_{\text {bulk }}=1.4 \mathrm{~mol} / \mathrm{m}_{\mathrm{L}}^{3}$ this condition is satisfied if $-r_{\mathrm{O}_{2}}^{\mathrm{w}}<15 \times 10^{-3}$ $\mathrm{mol} /\left(\mathrm{kg}_{\text {resin }} \cdot \mathrm{s}\right)$. From this it can be concluded that there are significant concentration differences between the bulk liquid and the outer resin surface for most experiments. For $-r_{\mathrm{O}_{2}}^{\mathrm{w}}=70 \times 10^{-3} \mathrm{~mol} /\left(\mathrm{kg}_{\mathrm{resin}} \cdot \mathrm{s}\right)$, being the highest oxygen consumption rate observed in this study, $\left[\mathrm{O}_{2}\right]_{\mathrm{resin}}=1.1 \mathrm{~mol} / \mathrm{m}_{\mathrm{L}}^{3}$.

The influence of intraparticle mass transport on the observed rates has been estimated using the Weisz-Prater criterion [22] for the reaction rates related to the CoPcTS containing mass fraction of catalyst particles. Because the thickness of the CoPcTS containing shell, $\delta_{\text {CoPcTs }}$, is only $1.3 \times 10^{-6} \mathrm{~m}$, which is much smaller than the radius of the resin particles, the reaction zone may be considered as a flat plate being open for mass transport only at the outer surface of the resin particle. Starting from the Weiss modulus, $\Phi$, for an $n$th order irreversible reaction, presented by Froment and Bischoff [23], the following expression can be derived:

$$
\begin{aligned}
\Phi= & {\left[(n+1) \times\left(-r_{\mathrm{O}_{2}}^{\mathrm{w}}\right)\right.} \\
& \times \frac{d_{\mathrm{p}}^{3}}{\left\{d_{\mathrm{p}}^{3}-\left(d_{\mathrm{p}}-2 \times \delta_{\mathrm{CoPcTS}}\right)^{3}\right\}} \\
& \left.\times \delta_{\text {CoPcTs }}^{2} \times \rho_{\text {resin }}\right] \\
& \times\left[2 \times D_{\mathrm{O}_{2}}(\text { eff }) \times\left[\mathrm{O}_{2}\right]_{\text {resin }} \times \lambda_{\mathrm{O}_{2}}\right]^{-1}
\end{aligned}
$$


where $D_{\mathrm{O}_{2}}$ (eff) and $\lambda_{\mathrm{O}_{2}}$ stand for the effective diffusion coefficient of oxygen in the resin phase and the partition coefficient of oxygen between the resin phase and the surrounding liquid. The reaction order $n$ may be approximated as zero for all experiments. This can be derived from the results of Van Herk et al. [13], who reported that the CoPcTS sites in the homogeneous 2,4-ionene system are almost completely saturated with oxygen for $\left[\mathrm{O}_{2}\right]>1.0 \mathrm{~mol} / \mathrm{m}^{3}$. The influence of intraparticle diffusion limitation on the rates of zeroth order reactions becomes significant if $\Phi>1$ [23]. The values of $\lambda_{\mathrm{O}_{2}}$ and $D_{\mathrm{O}_{2}}$ (eff) are taken as unity and $0.5 \times 10^{-9}$ $\mathrm{m}^{2} / \mathrm{s}$, respectively. The value of $D_{\mathrm{O}_{2}}$ (eff) has been estimated for the macroporous poly (styrene-divinylbenzene) resin (XAD-2) [4] and is probably significantly lower than that for the catalyst support investigated in this study, because the average pore size of the TRIM/MMA resin $(700 \mathrm{~nm})$ is much larger than that of the XAD-2 resin $(10 \mathrm{~nm})$. Therefore, the calculation may lead to some overestimation of the influence of pore diffusion limitation.

For $\left[\mathrm{O}_{2}\right]_{\text {resin }}=1.1 \mathrm{~mol} / \mathrm{m}_{\mathrm{L}}^{3}$ pore diffusion limitation is negligible if $-r_{\mathrm{O}_{2}}^{\mathrm{w}}<0.18 \mathrm{~mol} /$ $\left(\mathrm{kg}_{\text {resin }} \cdot \mathrm{s}\right)$. The results of this calculation point to the absence of an intraparticle diffu- sion limitation for the conditions used in this study.

Because the reaction is approximately zero order in oxygen, the estimated concentration gradients between the bulk liquid and the outer surface of the resin do not influence the performance of the catalyst. Therefore, the variation of $-r_{\mathrm{O}_{2}}^{\mathrm{w}}$ with the mercaptoethanol concentration originates only from intrinsic kinetic effects. The results in Fig. 6 point to simple single substrate MichaelisMenten kinetics:

$$
-r_{\mathrm{O}_{2}}^{\mathrm{w}}=\frac{k \times[\text { CoPcTS }] \times[\mathrm{ME}]}{K_{\mathrm{M}}+[\mathrm{ME}]}
$$

The turnover frequency, $k$, at substrate saturation and the Michaelis constant, $K_{\mathrm{M}}$, calculated by plotting $1 /\left(-r_{\mathrm{O}_{2}}^{\mathrm{w}}\right)$ against $1 /$ [ME] are $295 \mathrm{~mol} \mathrm{O}_{2} /(\mathrm{mol} \mathrm{CoPcTS} \cdot \mathrm{s})$ and 169 $\mathrm{mol} / \mathrm{m}_{\mathrm{L}}^{3}$, respectively. The difference between the experimental values of $-r_{\mathrm{O}_{2}}^{\mathrm{w}}$ and those calculated with these values of $k^{2}$ and $K_{\mathrm{M}}$ was always less than $10 \%$.

Turnover frequencies and Michaelis constants for the oxidative coupling of mercaptoethanol catalysed by some different CoPcTS containing catalysts are collected in Table 3. These data show that the immobilisation of qP4VP on the TRIM/MMA resin leads to a much smaller reduction of the

\section{TABLE 3}

Turnover frequencies at substrate saturation, and Michaelis constants for the CoPcTS catalysed oxidative coupling of 2-mercaptoethanol for several cocatalysts at $25^{\circ} \mathrm{C}$ and optimal $\mathrm{pH}$ conditions

\begin{tabular}{llll}
\hline Cocatalyst & $\begin{array}{l}k \times 10^{-1} \\
\left(\mathrm{~mol} \mathrm{O}_{2} /(\mathrm{mol} \mathrm{CoPcTS} \cdot \mathrm{s})\right)\end{array}$ & $\begin{array}{l}K_{\mathrm{M}} \times 10^{-1} \\
\left(\mathrm{~mol} / \mathrm{m}^{3}\right)\end{array}$ & Reference \\
\hline $\begin{array}{l}\text { TRIM-MMA/qP4VP } \\
\text { homogeneous qP4VP }\end{array}$ & 30 & 17 & this work \\
$\begin{array}{l}\text { PS-b-qP4VP } \\
\text { PS-b-qP4VP/latex }\end{array}$ & 35 & 2.6 & {$[17]$} \\
$\begin{array}{l}2,4-\text { ionene, } M_{\mathrm{n}}=1740, \\
\text { homogeneous }\end{array}$ & 28 & 11 & {$[17]$} \\
$\begin{array}{l}\text { 2,4-ionene, } M_{\mathrm{n}}=6600, \\
\text { homogeneous }\end{array}$ & 93 & 12 & {$[17]$} \\
2,4-ionene $/ X A D-2$ & 83 & 1.1 & {$[16]$} \\
\hline
\end{tabular}




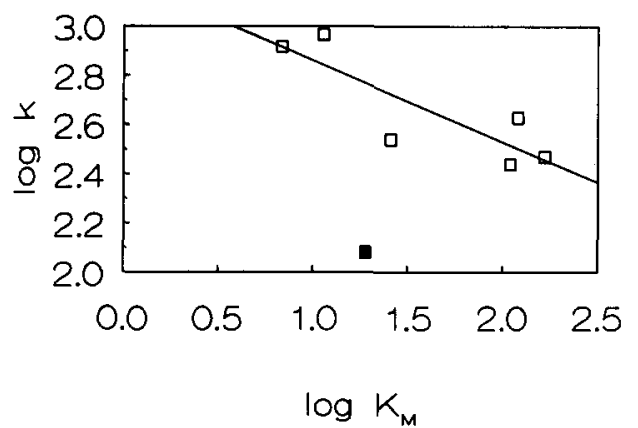

Fig. 10. Relation between the turnover frequency at substrate saturation and optimal $\mathrm{pH}$ and the Michaelis constant for the CoPcTS catalysed oxidation of 2mercaptoethanol by several cocatalyst systems. ( $\square$ ) Data corresponding to those collected in Table 3, except that for the 2,4-ionene/XAD-2 resin; ( $\mathbb{C}$ ) data for the 2,4-ionene / XAD-2 resin.

turnover frequency than the immobilisation of 2,4-ionene on the XAD-2 resin. This result may be attributed to the large pore diameters of the TRIM/MMA support as compared with those of the XAD-2 resin.

The tendency towards mercaptoethanol chemisorption decreases strongly on immobilising the qP4VP on the TRIM/MMA support. For the 2,4-ionene/XAD-2 resin the influence of immobilisation on the chemisorption of mercaptoethanol is much smaller. Figure 10 shows that with the exception of the data for the 2,4-ionene/XAD-2 system, the turnover frequencies and the Michaelis constants given in Table 3 approximately obey a linear free energy relation. Reactions obeying a linear free energy relation usually follow an identical reaction mechanism [24]. As compared with the homogeneous 2,4-ionene system immobilisation of the cationic polymer in the pores of the XAD-2 resin probably leads to a significant change in the reaction mechanism, resulting in considerable loss of activity. However, immobilisation of qP4VP on the TRIM/MMA resin and polystyrene-b-qP4VP on latex particles do not result in a significant change of the reaction mechanism. Therefore immobilisation only leads to a rather limited loss of activity for these systems.

The kinetic results point to the fact that the catalytic activity after immobilisation can be retained more or less when the chain flexibility of the cationic polymer and its accessibility for CoPcTS and the reactants are comparable with the corresponding properties in the homogeneous situation.

\section{Conclusions}

Macroporous resins with pore sizes of $\sim 1$ $\mu \mathrm{m}$ can be prepared by suspension polymerisation of TRIM and MMA.

The pore size and the number of residual double bonds of TRIM strongly depends on the nature and the composition of the porogenic diluent.

Quaternised poly(4-vinylpyridine) can be grafted on the residual double bonds of TRIM in the resin.

The catalytically active complex (CoPcTS) for the oxidative coupling of thiols is only adsorbed in the pores located in the outer shell of the resin.

The influence of mass transport on the observed kinetics is negligible under the experimental conditions used.

The oxidative coupling of 2-mercaptoethanol obeys single substrate Michaelis-Menten kinetics.

Immobilisation of a cationic polymeric cocatalyst for the CoPcTS catalysed oxidative coupling of 2-mercaptoethanol can be combined with considerable retention of activity when the microenvironment of the active CoPcTS centres is comparable with that in the homogeneous situation.

\section{List of symbols}

$D_{\mathrm{O}_{2}} \quad$ molecular diffusion coefficient of oxygen in water $\left(\mathrm{m}^{2} / \mathrm{s}\right)$ 
$D_{\mathrm{O}_{2}}$ (eff) effective diffusion coefficient of oxygen in the resin phase $\left(\mathrm{m}^{2} / \mathrm{s}\right)$

$d_{\mathrm{p}} \quad$ average diameter of the resin particles (m)

$k$ turnover frequency $\left(\mathrm{mol} \mathrm{O}_{2} /(\mathrm{mol}\right.$ CoPcTS $\cdot s)$ )

$k_{\mathrm{LS}} \quad$ mass transfer coefficient for oxygen transport between the bulk liquid and the outer resin surface $(\mathrm{m} / \mathrm{s})$

$K_{\mathrm{M}} \quad$ Michaelis constant $\left(\mathrm{mol} / \mathrm{m}^{3}\right)$

$n \quad$ reaction order in oxygen

$\left[\mathrm{O}_{2}\right]_{\text {bulk }}$ oxygen concentration in the bulk liquid $\left(\mathrm{mol} / \mathrm{m}_{\mathrm{L}}^{3}\right)$

$\left[\mathrm{O}_{2}\right]_{\mathrm{resin}}$ oxygen concentration in the liquid at the outer resin surface (mol/ $\mathrm{m}_{\mathrm{L}}^{3}$ )

$R \quad$ pore radius (m)

$-R_{\mathrm{O}_{2}} \quad$ molar absorption flow rate of oxygen $(\mathrm{mol} / \mathrm{s})$

$-r_{\mathrm{O}_{2}}^{\mathrm{w}} \quad$ specific oxygen consumption rate $\left(\mathrm{mol} /\left(\mathrm{kg}_{\mathrm{resin}} \cdot \mathrm{s}\right)\right)$

$V_{\mathrm{L}} \quad$ volume of the liquid phase $\left(\mathrm{m}_{\text {water }}^{3}\right)$

$V_{\mathrm{p}} \quad$ specific pore volume $\left(\mathrm{m}^{3} / \mathrm{kg}\right)$

$\stackrel{\mathrm{p}}{W_{\text {resin }}}$ resin concentration $\left(\mathrm{kg}_{\text {resin }} /\right.$ $\mathrm{m}_{\text {water }}^{3}$ )

$\delta_{\text {CoPcTS }}$ thickness of CoPcTS containing shell in the resin particles $(\mathrm{m})$

$\epsilon$ power input of the impeller $(\mathrm{W} / \mathrm{kg})$

$\lambda_{\mathrm{O}_{2}} \quad$ partition coefficient of oxygen between the resin phase and the surrounding liquid $\left(\mathrm{m}_{\text {water }}^{3} / \mathrm{m}_{\text {resin }}^{3}\right)$

$\rho_{\text {resin }}$ density of the water swollen resin $\left(\mathrm{kg} / \mathrm{m}^{3}\right)$

$\Phi \quad$ Weiss modulus

$\nu \quad$ kinematic viscosity $\left(\mathrm{m}^{2} / \mathrm{s}\right)$

\section{References}

1 J.H. Schutten and J. Zwart, Autoxidation of mercaptans promoted by a bifunctional catalyst prepared by polymer attachment of cobalt-phthalocyanine, J. Mol. Catal., 5 (1979) 109.
2 W.M. Brouwer, P. Piet and A.L. German, The promoting role of polycations in the cobalt(II) phthalocyanine tetrasodium sulfonate catalysed oxidation of thiols, J. Mol. Catal., 31 (1985) 169.

3 J. van Welzen, A.M. van Herk and A.L. German, Effects of ionenes on structure and catalytic activity of cobaltphthalocyanine. Part 5a. The catalytic role of cobaltphthalocyanine aggregates, Makromol. Chem., 190 (1989) 2477.

4 K.H. Van Streun, J. Meuldijk and A.L. German, Immobilization of 2,4-ionene on a macroporous poly(styrene-divinylbenzene) resin and its effect on the rate of the cobaltphthalocyanine-catalyzed oxidative coupling of mercaptoethanol, Angew. Makromol. Chem., 173 (1989) 119.

5 A. Guyot, in D.C. Sherrington and P. Hodge (Eds.), Synthesis and Separations Using Functional Polymers, Wiley, New York, 1988, Chap. 1.

6 A. Guyot and M. Bartholin, Design and properties of polymers as materials for fine chemistry, Prog. Polym. Sci., 8 (1982) 277.

7 J.E. Rosenberg and P. Flodin, Macroporous gels. 2. Polymerization of trimethylolpropane trimethacrylate in various solvents, Macromolecules, 20 (1987) 1518.

8 J.E. Rosenberg and P. Flodin, Macroporous gels. 3. Copolymerization of trimethylolpropane trimethacrylate and methyl methacrylate in toluene or ethyl acetate, Macromolecules, 20 (1987) 1522.

9 J.E. Rosenberg and P. Flodin, Macroporous gels. 4. An NMR study of the formation of macroporous gels containing trimethylolpropane trimethacrylate, Macromolecules, 21 (1988) 2041.

10 R.Z. Greenley, Free radical copolymerization reactivity ratios, in J. Brandrup and E.H. Immergut (Eds.), Polymer Handbook, 3rd edn., Wiley, New York, 1989, Chap. 2.

11 R. Arshady and A. Ledwith, Suspension polymerization and its application to the preparation of polymer supports, React. Polym., 1 (1983) 159.

12 R.L. Albright, Ger. Pat. P1943807.4, Rohm \& Haas Co., 1970.

13 A.M. van Herk, A.H.J. Tullemans, J. van Welzen and A.L. German, Effects of ionenes on catalytic activity and structure of cobaltphthalocyanine. Part 2. Kinetics as a function of thiol and oxygen concentrations, J. Mol. Catal. 44 (1988) 266.

14 A. Revillon, A. Guyot, Quing Yuan and P. Da Prato, Reagents on styrene-divinylbenzene supports with improved accessibility, React. Polym., 10 (1989) 11.

15 J.H. Schutten, C.H. Hastenberg, P. Piet and A.L. German, Macroporous styrene-divinylbenzene copolymers as carriers for poly(vinylamine)- 
cobaltphthalocyanine oxidation catalysts, Angew. Makromol. Chem., 89 (1980) 201.

16 K.H. Van Streun, P. Piet and A.L. German, Effects of 2,4-ionene of different molar masses on the oxidative coupling of thiol catalyzed by cobaltphthalocyanine, Eur. Polym. J., 23 (1987) 941.

17 K.H. van Streun, R. Tennebroek, P. Piet and A.L. German, Immobilization of a block copolymer of styrene and quaternized 4-vinylpyridine on latex and its effect on the cobaltphthalocyanine-catalyzed oxidation of 2-mercaptoethanol, Makromol. Chem., 191 (1990) 2181.

18 S. Asai, Y. Konishi and Y. Sasaki, Mass transfer between fine particles and liquids in agitated vessels, J. Chem. Eng. Jpn., 21 (1988) 107.

19 R.H. Perry and C.H. Chilton, Chemical Engineers Handbook, 6th edn., McGraw-Hill, New York, 1984 , p. 3-259.
20 R.L. Bates, P.H. Fondy and R.R. Cropstein, An examination of some geometric parameters of impeller power, Ind. Eng. Chem., Process Des. Dev., 2 (1963) 310.

21 Y. Sano, N. Yamaguchi and T. Adachi, Mass transfer coefficients for suspended particles in agitated vessels and bubble columns, J. Chem. Eng. Jpn., 7 (1974) 255.

22 P.B. Weisz and C.D. Prater, Interpretation of measurements in experimental catalysis, $A d v$. Catal., 6 (1954) 143.

23 G.F. Froment and K.B. Bischoff, Chemical Reactor Analysis and Design, Wiley, New York, 1979, p. 195.

24 R.G.Wilkins, The Study of Kinetics and Mechanism of Reactions of Transition Metal Complexes, Allyn and Bacon, Boston, 1974, pp. 88-89. 